\title{
The pathogenesis and pathophysiology of type 1 and type 2 diabetes mellitus
}

\author{
Ozougwu, J. C. ${ }^{1^{\star}}$, Obimba, K. C. ${ }^{2}$, Belonwu, C. D. ${ }^{3}$, and Unakalamba, C. B. ${ }^{4}$
}

Physiology and Biomedical Research Unit, Department of Biological Sciences, College of Basic and Applied Sciences, Rhema University Aba, Abia State, Nigeria.

${ }^{2}$ Department of Biochemistry, School of Science, Federal University of Technology Owerri. Imo State. Nigeria.

${ }^{3}$ Department of Biochemistry, Faculty of Chemical Sciences, University of Portharcourt. Rivers State. Nigeria.

${ }^{4}$ Department of Zoology and Environmental Biology, University of Nigeria, Nsukka, Enugu state, Nigeria.

Accepted 17 June, 2013

The aim of this paper is to review the information on type 1 and type 2 diabetes with emphasis on its etiology, pathogenesis and pathophysiology via literature review. Diabetes is a group of metabolic disorders characterized by a chronic hyperglycemic condition resulting from defects in insulin secretion, insulin action or both. Type 1 diabetes is the result of an autoimmune reaction to proteins of the islets cells of the pancreas while type 2 diabetes is caused by a combination of genetic factors related to impaired insulin secretion, insulin resistance and environmental factors such as obesity, overeating, lack of exercise and stress, as well as aging. The pathogenesis of selective $\beta$-cell destruction within the islet in type 1 diabetes mellitus is difficult to follow due to marked heterogeneity of the pancreatic lesions. At the onset of overt hyperglycemia, a mixture of pseudoatrophic islets with cells producing glycogen, somatostatin and pancreatic polypeptide, normal islets and islets containing both $\beta$-cells and infiltrating lymphocytes and monocytes may be seen. The autoimmune destruction of pancreatic $\beta$ cells leads to a deficiency of insulin secretion that leads to the metabolic derangements associated with type 1 diabetes. The main pathophysiological features of type 2 diabetes are impaired insulin secretion and increased insulin resistance. The impairment of pancreatic $\beta$ cell function notably shows progression overtime in type 2 diabetes although aging, obesity, insufficient energy consumption, alcohol drinking, smoking, etc are independent risk factors of pathogenesis of type 2 diabetes mellitus.

Key words: Diabetes Mellitus, Pathophysiology, Pathogenesis, Etiology.

\section{INTRODUCTION}

Diabetes mellitus (DM) is a group of metabolic disorders characterized by a chronic hyperglycemic condition resulting from defects in insulin secretion, insulin action or both. Permanent neonatal diabetes is caused by glucokinase deficiency, and is an inborn error of the glucose-insulin signaling pathway (Njolstad et al., 2003).
The prevalence of diabetes is increasing rapidly worldwide and the World Health Organization (2003) has predicted that by 2030 the number of adults with diabetes would have almost doubled worldwide, from 177 million in 2000 to 370 million. Experts project that the incidence of diabetes is set to soar by $64 \%$ by 2025 , meaning that a 
Table 1. Some causes of insulin resistance.

\begin{tabular}{cl}
\hline S/No. & Causes \\
\hline 1 & Obesity/overweight (especially excess visceral adiposity) \\
2 & Excess glucorticoids (cushing's syndrome or steroid therapy) \\
3 & Excess growth hormone (acromegaly) \\
4 & Pregnancy, gestational diabetes \\
5 & Polycystic ovary disease \\
6 & Lipodystrophy (acquired or genetic, associated with lipid accumulation in liver) \\
7 & Autoantibodies to the insulin receptor \\
8 & Mutations of insulin receptor \\
9 & Mutations of the peroxisome proliferators' activator receptor y (PPAR Y) \\
10 & Mutations that cause genetic obesity (e.g., melanocortin receptor mutations) \\
11 & Hemochromatosis (a hereditary disease that causes tissue iron accumulation). \\
\hline
\end{tabular}

Source: Guyton and Hall (2006).

Table 2. Clinical characteristics of patients with Type 1 and Type 2 diabetes mellitus.

\begin{tabular}{lll}
\hline Features & Type 1 & Type 2 \\
\hline Age of onset & Usually less than 20 years & Usually greater than 30 years \\
Body mass & Low (wasted) to normal & Obese \\
Plasma insulin & Low or absent & Normal to high initially \\
Plasma glucagon & High, can be suppressed & High, resistant to suppression \\
Plasma glucose & increased & Increased \\
Insulin sensitivity & Normal & Reduced \\
Therapy & insulin & Weight loss, thiazolidinediones, metformin, sulfonylureas, insulin \\
\hline
\end{tabular}

Source: Guyton and Hall (2006).

staggering 53.1 million citizens will be affected by the disease (Rowley and Bezold, 2012). The estimated worldwide prevalence of diabetes among adults in 2010 was 285 million (6.4\%) and this value is predicted to rise to around 439 million (7.7\%) by 2030 (Shaw et al., 2010). There are two main types of diabetes mellitus: i. Type 1 diabetes, also called insulin dependent diabetes mellitus (IDDM), is caused by lack of insulin secretion by beta cells of the pancreas.

ii. Type 2 diabetes, also called non-insulin dependent diabetes mellitus (NIDDM), is caused by decreased sensitivity of target tissues to insulin.

The reduced sensitivity to insulin is often called insulin resistance and its causes are shown in Table 1. In both types of diabetes mellitus, metabolism of all the main foodstuffs is altered. The basic effect of insulin lack or insulin resistance on glucose metabolism is to prevent the efficient uptake and utilization of glucose by most cells of the body, except those of the brain (Guyton and
Hall, 2006). As a result of this, blood glucose concentration increases, cell utilization of glucose falls increasingly lower and utilization of fats and proteins increases. The clinical characteristics of patients with type 1 and type 2 diabetes mellitus are shown in Table 2 .

\section{EPIDEMIOLOGY AND ETIOLOGY OF TYPE 1 DIABETES (IDDM)}

Type 1 diabetes represents around $10 \%$ of all cases of diabetes, affecting approximately 20 million people worldwide (American Diabetes Association, 2001).

Although type 1 diabetes affects all age groups, the majority of individuals are diagnosed either at around the age of 4 to 5 years, or in their teens and early adulthood (Blood et al., 1975). The incidence of type 1 diabetes is rising. Across Europe, the average annual increase in the incidence in children under 15 years is 3.4\% (EURODIAB 
ACE study Group, 2000), with the steepest rise in those under 5 years old (Karvonen et al., 1999). Type 1 diabetes is the result of an autoimmune reaction to proteins of the islets cells of the pancreas (Holt, 2004). There is a strong association between IDDM and other endocrine autoimmunity (for example, Addison disease) and an increased incidence of autoimmune diseases are seen in family members of IDDM patients. The three types of autoantibodies known are:

i) Islet cell cytoplasmic antibodies (ICCA): The primary antibodies found in $90 \%$ of type 1 diabetics are against islet cell cytoplasmic proteins. The presence of ICCA is a highly accurate predictor of future development of IDDM.

ii) Islet cell surface antibodies (ICSA): Autoantibodies directed against islets cell surface antigens (ICSA) have also been described in as many as $80 \%$ of type 1 diabetics. Some patients with type 2 diabetes have been identified, which are ICSA positive.

iii). Specific antigenic targets of islet cells: Antibodies to glutamic acid decarboxylase (GAD) have been identified in over $80 \%$ of patients newly diagnosed with IDDM. Anti GAD antibodies decline over time in type 1 diabetics. The presence of anti GAD antibodies is a strong predictor of the future development of IDDM in high risk populations. Anti insulin antibodies (IAAs) have been identified in IDDM patients and in relatives at risk to developing IDDM. These IAAs are detectable even before the onset of insulin therapy in type 1 diabetics. IAA is detectable in around $40 \%$ of young children with IDDM (Raju and Raju, 2010).

\section{Pathogenesis of type 1 diabetes mellitus}

Type 1 diabetes mellitus is a chronic autoimmune disease associated with selective destruction of insulinproducing pancreatic $\beta$-cells (Figure 1). The onset of clinical disease represents the end stage of $\beta$-cell destruction leading to type 1 diabetes mellitus. Al Homsi and Lukic (1992) explained that several features characterize type 1 diabetes mellitus as an autoimmune disease:

1. Presence of immuno-competent and accessory cells in infiltrated pancreatic islets;

2. Association of susceptibility to disease with the class II (immune response) genes of the major histocompatibility complex (MHC; human leucocyte antigens HLA);

3. Presence of islet cell specific autoantibodies;

4. Alterations of $T$ cell mediated immunoregulation, in particular in CD4+ T cell compartment;

5. The involvement of monokines and $\mathrm{TH} 1$ cells producing interleukins in the disease process;

6. Response to immunotherapy and;

7. Frequent occurrence of other organ specific auto- immune diseases in affected individuals or in their family members.

The pathogenesis of selective $\beta$-cell destruction within the islet in type $1 \mathrm{DM}$ is difficult to follow due to marked heterogeneity of the pancreatic lesions. At the onset of overt hyperglycemia, a mixture of pseudoatrophic islets with cells producing glycogen (a cells), somatostatin (d cells) and pancreatic poly-peptide (PP cells), normal islets, and islets containing both b-cells and infiltrating lymphocytes and monocytes may be seen (Al-Homsi and Lukic, 1992). Lymphocytic infiltration is found only in the islet containing residual $\beta$-cells and is likely that the chronicity with which type 1 DM develops reflects this heterogeneity of islet lesions (Al-Homsi and Lukic, 1992). In contrast to this chronicity in the natural history of the disease, $\beta$-cells are rapidly destroyed when pancreas is transplanted from identical twin donors into their long term diabetic twin mates in the absence of immunosuppression. In these cases, massive insulitis develops rapidly with infiltrating $T$ lympocytes indicating an anamnestic autoimmune reaction (Al Homsi and Lukic, 1992). In addition, this observation also indicates that the chronic time course in type 1 DM (but not in a transplanted pancreas) is a consequence of down regulatory phenomena taking part in immunopathogenesis of the disease (Al Homsi and Lukic, 1992). Activation of islet antigen - specific CD4+ T cells appear to be absolute prerequisite for the development of diabetes in all animal models of type 1 DM (Gill and Haskins, 1993). CD4+ islet specific T-cell clones derived from diabetic NOD mice, when injected into prediabetic or non diabetes prone FI mice, induce insulitis and diabetes. It was also reported that CD4+ T cells are sufficient to induce insulitis while CD8+ $T$ cells contribute to the severity of the damage (Yagi et al., 1992). These findings together with the evidence that insulitis in chronic graft versus host disease may occur in the absence of CD8+ T cells suggest that CD4+ $T$ cells may be the only immunocompetent cells required in the disease process. However, it seems that only one subset of CD4+ T cells are responsible for disease induction.

CD4+ $\mathrm{T}$ cell bearing alloantigen RT6 are absent in diabetes prone $\mathrm{BB}$ rats and appear to protect $\mathrm{AO}$ rats from MLD-STZ induced diabetes (Greineh et al., 1987). Down-regulation of diabetogenic autoimmune response by the spleen cells derived from animals treated with adjuvants could also be explained by $\mathrm{CD} 4+\mathrm{T}$ cell subsets interplay (Ulaeto et al., 1992). High level of THI type cytokines IL-2 and interferon $\mathrm{g}$ are found to correlate or/and to enhance induction of autoimmune diabetes in experimental models (Fowell et al., 1991; Campbell et al., 1991). The TH-1 type cells, and in particular their product IFN-g, activate macrophages. In animal, models of type 1 DM electron microscopic studies of pancreata showed 


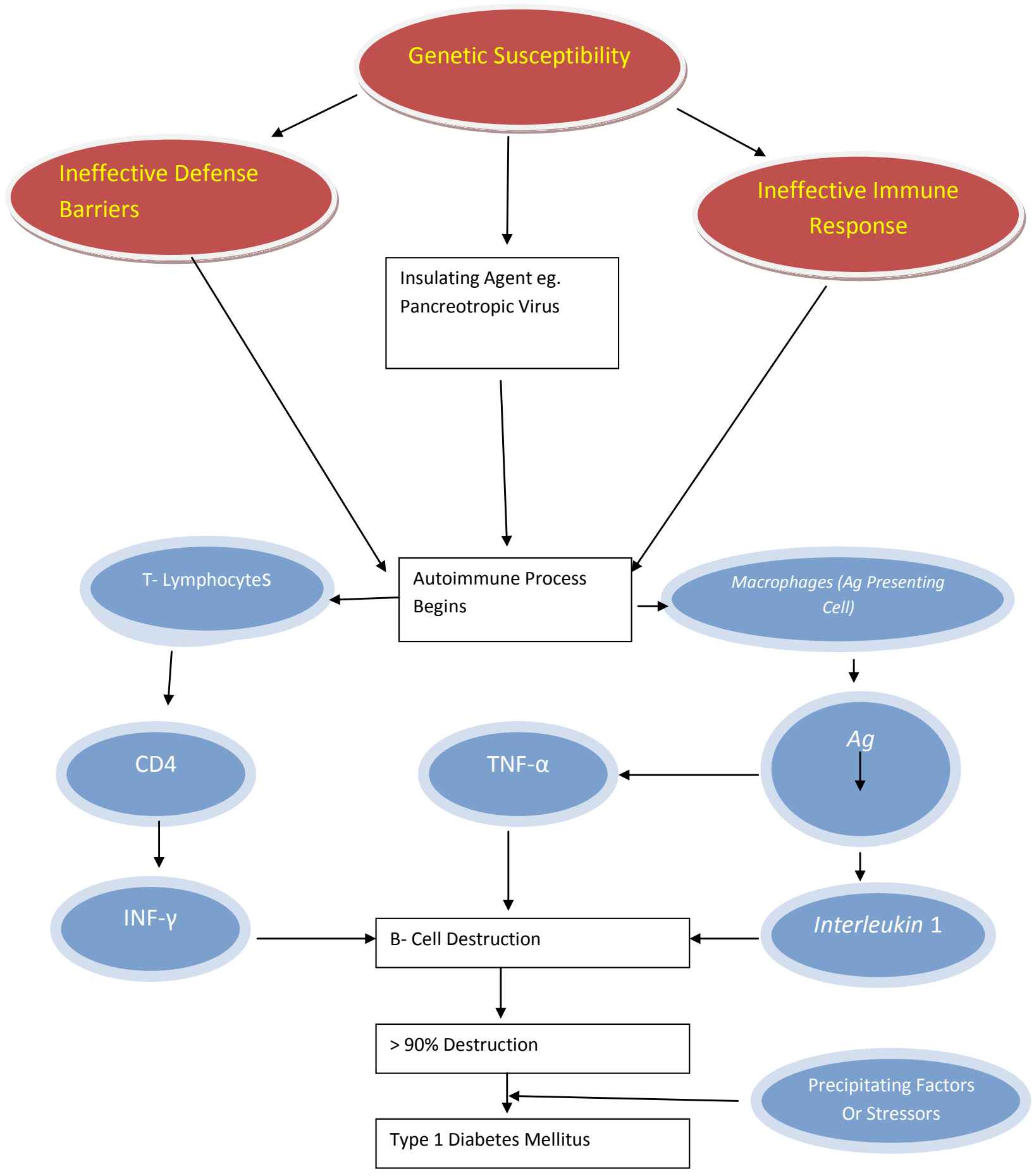

Figure 1. Pathogenesis of type 1 diabetes mellitus.

that macrophages are the first cell type invading the islets(Kolb-Bachofen et al., 1988). In vitro studies and studies on perfused pancreas suggest that Interleukin 1 (IL-1) and tumor necrosis factor (TNFa), two cytokines mainly produced by macrophages, induce structural changes of $\beta$-cells and suppression of their insulin releasing capacity (Mandrup-Poulsen et al., 1987). However, it seems that IL-1 and TNF do not contribute 
appreciably to the cytotoxic activity of macrophages (Kroncke et al., 1991). Interferon $\mathrm{g}$ is also a powerful activator of macrophages for nitric oxide synthesis. Recently, evidence has been provided indicating that NO synthase activity is involved in diabetes development (Lukic et al., 1991). These data indicated, for the first time, that nitric oxide may be a pathogenic factor in autoimmunity and suggested a possibility that a new class of immunopharmacological agents, capable of modulating nitric oxide secretion may be tested in the prevention of type 1 DM development (Kolb and KolbBachofen, 1992).

\section{Pathophysiology of type 1 diabetes (IDDM)}

The autoimmune destruction of pancreatic $\beta$-cells, leads to a deficiency of insulin secretion which results in the metabolic derangements associated with IDDM. In addition to the loss of insulin secretion, the function of pancreatic a-cells is also abnormal and there is excessive secretion of glucagons in IDDM patients. Normally, hyperglycemia leads to reduced glucagons secretion, however, in patients with IDDM, glucagons secretion is not suppressed by hyperglycemia (Raju and Raju, 2010). The resultant inappropriately elevated glucagons levels exacerbate the metabolic defects due to insulin deficiency. The most pronounced example of this metabolic disruption is that patients with IDDM rapidly develop diabetic ketoacidosis in the absence of insulin administration. Although insulin deficiency is the primary defect in IDDM, there is also a defect in the administration of insulin. There are multiple biochemical mechanisms that account for impairment of tissue's response to insulin. Deficiency in insulin leads to uncontrolled lipolysis and elevated levels of free fatty acids in the plasma, which suppresses glucose metabolism in peripheral tissues such as skeletal muscle (Raju and Raju, 2010). This impairs glucose utilization and insulin deficiency also decreases the expression of a number of genes necessary for target tissues to respond normally to insulin such as glucokinase in liver and the GLUT 4 class of glucose transporters in adipose tissue. Raju and Raju (2010) explained that the major metabolic derangements, which result from insulin deficiency in IDDM are impaired glucose, lipid and protein metabolism which are explained in details as follows:

\section{Effects on glucose metabolism}

Uncontrolled IDDM leads to increased hepatic glucose output. First, liver glycogen stores are mobilized then hepatic gluconeogenesis is used to produce glucose. Insulin deficiency also impairs non hepatic tissue utiliza- tion of glucose. In particular in adipose tissue and skeletal muscle, insulin stimulates glucose uptake. This is accomplished by insulin mediated movement of glucose transporters proteins to the plasma membrane of these tissues. Reduced glucose uptake by peripheral tissues in turn leads to a reduced rate of glucose metabolism. In addition, the level of hepatic glucokinase is regulated by insulin. Therefore, a reduced rate of glucose phosphorrylation in hepatocytes leads to increased delivery to the blood. Other enzymes involved in anabolic metabolic metabolism of glucose are affected by insulin.

The combination of increased hepatic glucose production and reduced peripheral tissues metabolism leads to elevated plasma glucose levels. When the capacity of the kidneys to absorb glucose is surpressed, glucosuria ensues. Glucose is an osmotic diuretic and an increase in renal loss of glucose is accompanied by loss of water and electrolyte. The result of the loss of water (and overall volume) leads to the activation of the thirst mechanism (polydipsia). The negative caloric balance, which results from the glucosuria and tissue catabolism leads to an increase in appetite and food intake that is polyphagia (Raju and Raju, 2010).

\section{Effect on lipid metabolism}

One major role of insulin is to stimulate the storage of food energy in the form of glycogen in hepatocytes and skeletal muscle, following the consumption of a meal. In addition, insulin stimulates hepatocytes to synthesize and store triglycerides in adipose tissue. In uncontrolled IDDM there is a rapid mobilization of triglycerides leading to increased levels of plasma free fatty acids. The free fatty acids are taken up by numerous tissue (except the brain) and metabolized to provide energy. In the absence of insulin, malonyl COA levels fall, and transport of fatty acyl-COA into the mitochondria increases. Mitochondrial oxidation of fatty acids generates acetyl COA that can be further oxidized in the TCA cycle. However, in heaptocytes the majority of the acetyl COA is not oxidized by the TCA cycle but is metabolized into the ketone bodies (acetoacetate and b-hydroxybutyrate). These ketone bodies are used for energy production by the brain, heart and skeletal muscle. In IDDM, the increased availability of free fatty acids and ketone bodies exacerbates the reduced utilization of glucose, furthering the ensuing hyperglycaemia. Production of ketone bodies in excess of the body's ability to utilize them leads to ketoacidosis. A spontaneous breakdown product of acetoacetate is the acetone that is exhaled by the lungs, which gives a distinctive odor to the breath. Normally, plasma triglycerides are acted upon by lipoprotein lipase $(\mathrm{LPL})$ that requires insulin. LPL is a membrane bound enzyme on the surface of the endothelial cells lining the vessels, 
which allows fatty acids to be taken from circulating triglycerides for storage in adipocytes (Raju and Raju, 2010). The absence of insulin results in hypertriglyceridemia.

\section{Effects on protein}

Insulin regulates the synthesis of many genes, either positively or negatively, which affect overall metabolism. Insulin has an overall effect on protein metabolism, increasing the rate of protein synthesis and decreasing the rate of protein degradation. Thus insulin deficiency will lead to increased catabolism of protein. The increased rate of proteolysis leads to elevated concentration of amino acids in plasma (Raju and Raju, 2010). Glucogenic amino acids serve as precursors for hepatic and renal glyconeogenesis, which further contributes to the hyperglycaemia seen in IDDM.

\section{EPIDEMIOLOGY AND ETIOLOGY OF TYPE 2 DIABETES (NIDDM)}

Type 2 diabetes is the predominant form of diabetes and accounts for at least $90 \%$ of all cases of diabetes mellitus (Gonzalez et al., 2009). The rise in prevalence is predicted to be much greater in developing than in developed countries (69 versus $20 \%$ ) (Shaw et al., 2010). In developing countries, people aged 40 to 60 years (that is, working age) are affected most, compared with those older than 60 years in developed countries (Shaw et al., 2010). This increase in type 2 diabetes is inextricably linked to changes towards a Western lifestyle (high diet with reduced physical activity) in developing countries and the rise in prevalence of overweight and obesity (Chan et al., 2009; Colagiuri, 2010). There are approximately 1.4 million people with diagnosed type 2 diabetes in the UK (Bennett et al., 1995). The incidence of diabetes increases with age, with most cases being diagnosed after the age of 40 years. This equates to a lifetime risk of developing diabetes of 1 in 10 (Neil et al., 1987). Type 2 diabetes is a heterogenous disorder caused by a combination of genetic factors related to impaired insulin secretion, insulin resistance and environmental factors such as obesity, over eating, lack of exercise, and stress as well as aging (Kaku, 2010). It is typically a multifactorial disease involving multiple genes and environmental factors to varying extents (Holt, 2004). Type 2 diabetes is the common form of idiopathic diabetes and is characterized by a lack of the need for insulin to prevent ketoacidosis. It is not an autoimmune disorder and the susceptible genes that predispose to NIDDM have not been identified in most patients. This could be due to the heterogeneity of the genes respon- sible for the susceptibility to NIDDM.

\section{Pathogenesis of type 2 diabetes}

Under normal physiological conditions, plasma glucose concentrations are maintained within a narrow range, despite wide fluctuations in supply and demand, through a tightly regulated and dynamic interaction between tissue sensitivity to insulin (especially in liver) and insulin secretion (DeFronzo, 1988). In type 2 diabetes these mechanisms break down, with the consequence that the two main pathological defects in type 2 diabetes are impaired insulin secretion through a dysfunction of the pancreatic $\beta$-cell, and impaired insulin action through insulin resistance (Holt, 2004). Type 2 diabetes mellitus has a greater genetic association than type $1 \mathrm{DM}$, the pathogenesis of type 2 diabetes mellitus is characterized by impaired insulin secretion and insulin resistance as shown in Figure 2. The $100 \%$ concordance rate in identical twins is thought to be over-estimated, due to a selection or reporting bias. A population based twin study in Finland has shown a concordance rate of $40 \%$, and environmental effect may be a possible reason for the higher concordance rate for type 2 diabetes mellitus than for type 1 diabetes mellitus (Kaprio et al., 1992). Type 2 diabetes mellitus affects 1 to $2 \%$ of caucasians (Cook et al., 1993) but it is much higher in some ethnic groups such as Pima Indians (Knowler et al., 1990) and Arabs (Richens et al., 1988) and approaches $50 \%$ in South India. This indicates that genetic factors are more important than environmental factors. Except for maturity onset diabetes of the young (MODY), the mode of inheritance for type 2 diabetes mellitus is unclear. MODY, inherited as an autosomal dominant trait, may result from mutations in glucokinase gene on chromosome $7 \mathrm{p}$. Glucokinase is a key enzyme of glucose metabolism in beta cells and the liver (Froguel et al., 1993; Hattersley et al., 1992). MODY is defined as hyperglycemia diagnosed before the age of twenty-five years and treatable for over five years without insulin in cases where islet cell antibodies (ICA) are negative and HLA-DR3 and DR4 are heterozygous. MODY is rare in Caucasians, less than $1 \%$, and more common in blacks and Indians, more than $10 \%$ of diabetics. Chronic complications in MODY were thought to be uncommon but later were found to be more common, indicating its heterogeneity.

Considering MODY as a separate entity may masquerade its association with specific genetic diseases; and without a definite genetic marker, it should be treated as type 1 DM (Tattershall, 1991). Identification of a nonsense mutation in the glucokinase gene and its linkage with MODY was reported for the first time in a French family, implicating a mutation in a gene involved in glucose metabolism in the pathogenesis of type 2 


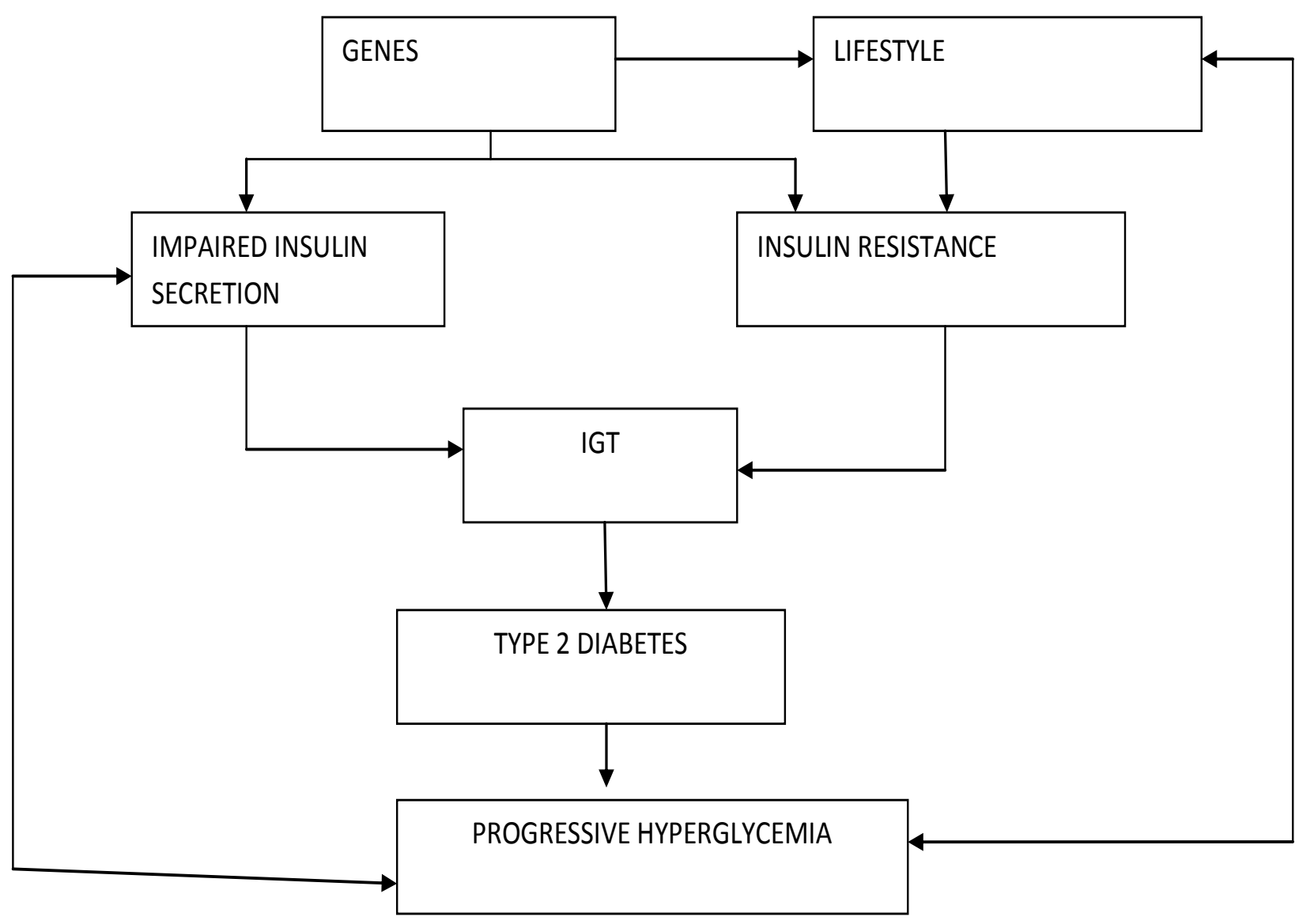

Figure 2. Pathogenesis of type 2 diabetes characterized by impaired insulin secretion and insulin resistance

diabetes mellitus (Vionnet et al., 1992). Later, sixteen mutations were identified in 18 MODY families. They included 10 mutations that resulted in an amino acid substitution, 3 that resulted in the synthesis of truncated protein, and 3 that affected RNA processing. Hyperglycemia in these families was usually mild and began in childhood, whereas the hyperglycemia of MODY families without glucokinase mutations usually appearedafter puberty (Froguel et al., 1993). Molecular genetic studies in type 2 diabetes mellitus, with the exception of MODY, have not been as successful as in type 1 diabetes mellitus. Mutations in the insulin gene lead to the synthesis and secretion of abnormal gene products, leading to what are called insulinopathies (Gabbay, 1980). Most of the patients with insulinopathies have hyperinsulinemia, inherited in autosomal fashion, heterozygous for normal and mutant alleles, and normally respond to exogenous insulin administration. Al Homsi and Lukic (1992) explained that most insulin gene mutations lead to:

(a) Abnormal insulins - Such as insulins Chicago and
Wakayama where the mutation leads to an amino acid replacement at an important site for receptor interaction; or

(b) The mutation may interfere in the proinsulin processing to insulin (Chan et al., 1987).

The association of the polymorphic (hypervariable) $5^{\prime}$ flanking region of the human insulin gene and type 2 diabetes mellitus is lacking in some population groups, indicating that it may be one of many factors in a multifactorial disease. Even MODY patients have shown no association with this region. It was mentioned earlier that there is a strong association between HLA-DR3/4 and type 1 diabetes mellitus. It was also reported that such an association is present with type 2 diabetes mellitus, rendering HLA-DR3/4 markers for beta cell destruction in these patients (Richens et al., 1988; Tattershall, 1991). Pancreatic abnormalities in islet secretory cells in type 2 diabetes mellitus are noted in beta, alpha and delta cells of the islets. Defects involving insulin secretion include relative decrease in basal 
secretion, decreased first and second phases of insulin response, glucose insensitivity and amino acid hypersensitivity of insulin release. The number and volume of beta cells are usually decreased to half the normal, and the alpha cell mass is increased leading to hyperglucagonemia. The islets exhibit hyalinization and amyloid deposition, containing islet amyloid polypeptide (IAPP) or amylin. This is a minor secretory peptide of the beta cells released along with insulin and C-peptide, but its role in the pathogenesis of type $2 \mathrm{DM}$ is not well understood (Steiner et al., 1991). This amylin is thought to produce insulin resistance (Molina et al., 1990). IAAP is reduced with progression of type 2 DM (Enoki et al., 1992). Intimate contact between beta cells and amyloid deposit in type 2 DM is noted by electron microscopy (Westermark, 1973). Away from the islets in the exocrine pancreas, fatty infiltration and diffuse fibrosis are evident. Defective islet cell function is the primary event which may be due to an autoimmune reaction producing hyperglycemia in type 2 DM (Zawala et al., 1992). The insulin receptor gene is located on chromosome 19 and it encodes a protein having alpha and beta subunits including the transmembrane domain and the tyrosine kinase domain (Kahu and White, 1988). Mutations affecting the insulin receptor gene have been identified and their association with type 2 diabetes mellitus and type $A$ insulin resistance is recognized.

Type $A$ insulin resistance is hereditary and type $B$ is an autoimmune disorder (Levy and Hug, 1993). Restriction fragment length polymorphism (RFLP) analysis of the insulin receptor gene (Ohagi et al., 1992), erythrocyte glucose transporter gene, and HLA genes, were not found useful as genetic markers for type 2 DM. Insulin resistance is insufficient to cause overt glucose intolerance, but may play a significant role in cases of obesity where there is known impairment of insulin action. Insulin resistance by itself may be a secondary event in type $2 \mathrm{DM}$, since it is also found in non-diabetic obese individuals. Insulin secretion defect may be the primary event, presenting as impaired pulsatile secretion of insulin. Hence, hyperglycemia is an inducer as well as a consequence of impaired islet cell function and insulin resistance. Many factors contribute to the insulin insensitivity including obesity and its duration (Evephart et al., 1992), age, lack of exercise, increased dietary fat and decreased fibres and genetic factors.

Fish oil is found to prevent insulin resistance in animals, but not in humans. It has a protective effect against thrombosis and vasospasm in type 2 DM (Mc Veigh et al., 1993). Insulin resistance in type $2 \mathrm{DM}$ is not totally clear, it may involve reduced insulin receptor number, it may be secondary to hyperinsulinemia and hyperglycemia, (Vuorinen-Markkola et al., 1992) or it may result from reduced tyrosine kinase activity (Comi et al., 1987; Bonadonna et al., 1993; Sten-linder et al., 1993) or even abnormalities distal to the receptor involving glucose transporter proteins through a family of glucose transporter genes (Mueckler, 1990). The GLUT2 gene, expressed in liver and pancreatic beta cells, and GLUT4, expressed in skeletal muscle and adipocytes, are strong candidate genes for the genetic susceptibility to type 2 DM. Analysis of these two glucose transporter genes, in addition to GLUT1, encoding for the brain/erythrocyte glucose transporter, has yielded, in Caucasians, no association of any RFLP marker on haplotype with either type 2 DM or obesity (Oelbaum, 1992).

Obesity has genetic as well as environmental causes. It has a strong effect on the development of type 2 DM (Bjorntorp, 1992; Haffner et al., 1992) as it is found in Western countries (NDDG, 1979; Wilson et al., 1981) and some ethnic groups such as Pima Indians (Joffe et al., 1992; Knowler et al., 1993). Obesity is more than just a risk factor; it has a causal effect in the development of type 2 DM against a genetic background. The evolution from obesity to type DM results from a succession of pathophysiological events:

(a) Augmentation of the adipose tissue mass, leading to increased lipid oxidation;

(b) Insulin resistance noted early in obesity, revealed by euglycemic clamp, as a resistance to insulin mediated glucose storage and oxidation, blocking the function of the glycogen cycle;

(c) Despite maintained insulin secretion, unused glycogen prevents further glucose storage leading to type $2 \mathrm{DM}$;

(d) Complete b-cell exhaustion appears later (Felber, 1992).

Type 2 DM patients have a characteristic shoulder, girdle-truncal obesity. Nutrient composition has also been found to be a risk factor for developing type $2 \mathrm{DM}$, where increased fat and decreased carbohydrate consumption have contributed to hyperinsulinemia of obesity. Dietary fibres, both soluble and insoluble, improve type 2 DM. It is also found that simple sugars do not directly cause diabetes. Deficiency of micronutrients, such as chromium and copper, is found to be an important cause of type 2 DM in a minority of cases. Stress has also been thought to induce type 2 DM. Actually, obesity and overavailability of food rather than stress are the contributing factors to type $2 \mathrm{DM}$. Therefore, when permanent change in dietary habits is established, some people should be allowed to escape the "life-long" diagnosis of type 2 DM (Akinmokun et al., 1992).

\section{Environmental factors in the pathogenesis type 2 diabetes}

Aging, obesity, insufficient energy consumption, alcohol 
Table 3. Factors causing increase in visceral fat.

\begin{tabular}{cl}
\hline S/No. & Factors \\
\hline 1 & Stress- Related Factors \\
A & Overeating, especially excessive intake of simple sugars \\
B & Smoking \\
C & Increase in alcohol intake \\
D & Disorders of nervous and endocrine systems: increase in cortisol, abnormality in sex hormone secretion \\
2 & lowered energy consumption due to a lack of exercise \\
3 & Genetic factors \\
4 & Aging \\
\hline
\end{tabular}

Source: Kaku (2010).

drinking, smoking, etc are independent risk factors of pathogenesis of type 2 diabetes. Obesity (particularly visceral fat obesity) due to a lack of exercise is accompanied by a decrease in muscle mass, induces insulin resistance, and is closely associated with the rapid increase in the number of middle and high aged patients. The changes in dietary energy sources, particularly the increase in fat intake, the decrease in starch intake, the increase in the consumption of simple sugars, and the decrease in dietary fiber intake, contribute to obesity and cause deterioration of glucose tolerance. Even mild obesity (Body mass index (BMI) <25) causes a 4 to 5 fold increase in risk of developing diabetes, if accompanied by the increase in visceral fat mass. People prone to visceral fat accumulation due to hyperalimentation, and risk factors for diabetes are linked to the accumulation of visceral fat and the factors causing visceral fats are shown in Table 3.

\section{Pathophysiology of type 2 diabetes (NIDDM)}

Individuals with NIDDM have detectable levels of circulating insulin, unlike patients with IDDM and the pathophysiology of type 2 diabetes is described in Figure 3 . On the basis of oral glucose tolerance testing the essential elements of NIDDM can be divided into four distinct groups:

i) Those with normal glucose tolerance.

ii) Chemical diabetes (called impaired glucose tolerance).

iii) Diabetes with minimal fasting hyperglycemia (fasting plasma glucose less than $140 \mathrm{mg} / \mathrm{dl}$ ).

iv) Diabetes mellitus in association with overt fasting hyperglycemia (fasting plasma glucose greater than 140 $\mathrm{mg} / \mathrm{dl}$ ).

The individuals with impaired glucose tolerance have hyperglycemia inspite of having highest levels of plasma insulin, indicating that they are resistant to the action of insulin. In the progression from impaired glucose tolerance to diabetes mellitus, the level of insulin declines indicating that patients with NIDDM have decreased insulin secretion. Insulin resistance and insulin deficiency are common in the average NIDDM patients (Holt, 2004). Insulin resistance is the primary cause of NIDDM, however some researcher contend that insulin deficiency is the primary cause because a moderate degree of insulin resistance is not sufficient to cause NIDDM (Raju and Raju, 2010). Most patients with the common form of NIDDM have both defects. Recent evidence has demonstrated a role for a member of the nuclear hormone receptor super family of proteins in the etiology of type 2 diabetes (Raju and Raju, 2010). Relatively new classes of drugs used to increase the sensitivity of the body to insulin are the thiazolidinedione drugs. These compounds bind to and alter the function of the peroxisome proliferators-activated receptor $g$ (PPARg). PPARg is also a transcription factor and when activated, binds to another transcription factor known as the retinoid $x$ receptor $(R X R)$. When these two proteins are complexed a specific set of genes becomes activated. PPARg is a key regulator of adipocyte differentiation; it can induce the differentiation of fibroblasts or other undifferentiated cells into mature fat cells. PPARg is also involved in the synthesis of biologically active compounds from vascular endothelial cells and immune cells (Raju and Raju, 2010).

\section{CONCLUSION}

The global burden of diabetes is increasing worldwide as it is a costly disease for developing economies of the world. To reduce the pandemic of type 1 and type 2 diabetes and its effects on lives and economies 


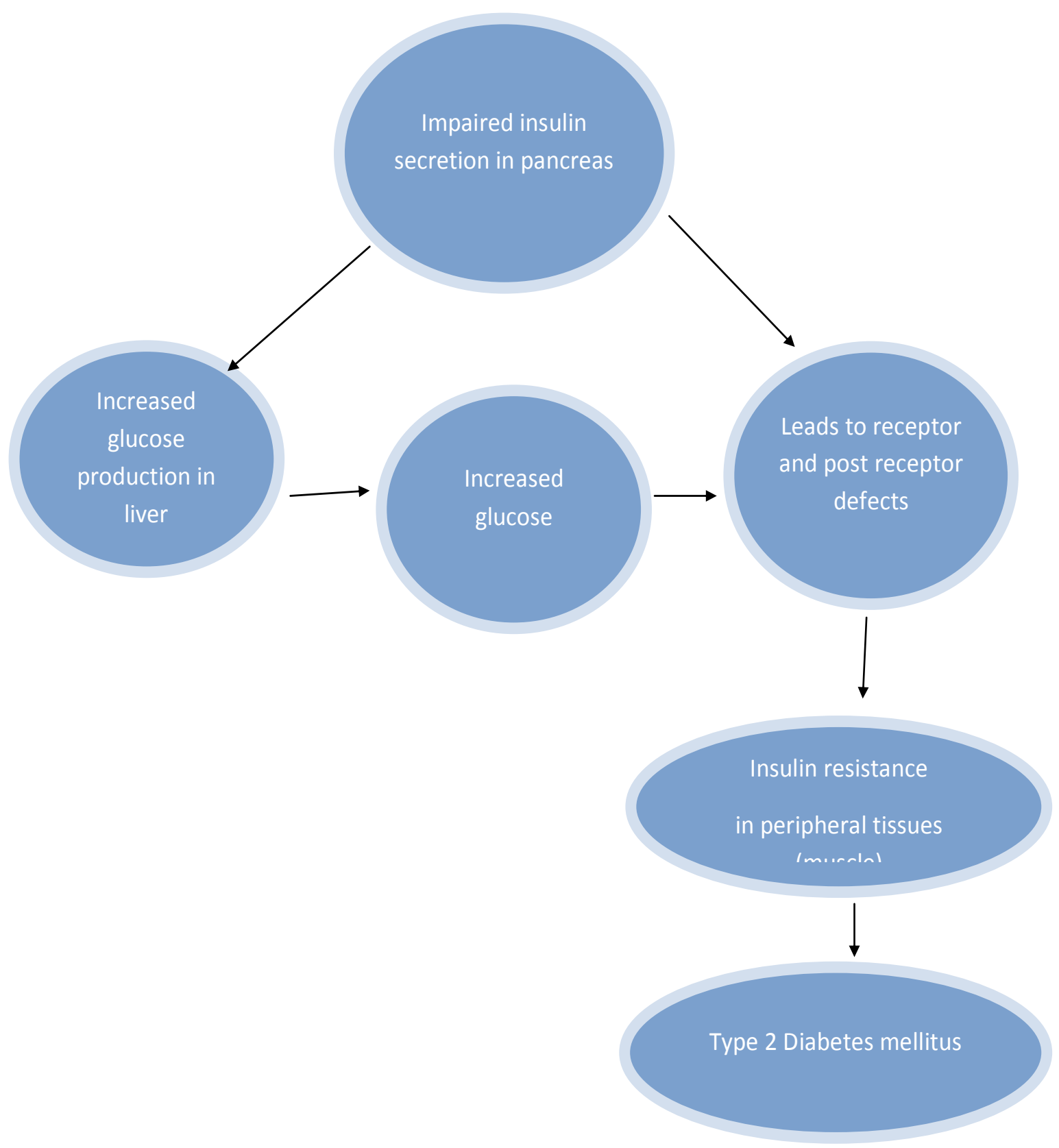

Figure 3. Pathophysiology of type 2 diabetes mellitus.

worldwide, it is necessary to have an improved understanding of its etiology, pathogenesis and pathophysiology to focus therapeutic and research efforts appropriately. A coordinated multidisciplinary approach is needed that involves scientists, public health practitioners, educators, clinicians and diabetics, with support from government authorities and nongovernmental organizations to reduce the incidence of diabetes significantly.

\section{REFERENCES}

Akinmokun A, Harris P, Home PD, Alberti KG (1992). Is diabetes always diabetes? Diabetes Res. Clin. Pract. 18:131-136.

Al Homsi MF, Lukic ML (1992). An Update on the pathogenesis of Diabetes Mellitus, Department of Pathology and Medical Microbiology (Immunology Unit)Faculty of Medicine and Health Sciences, UAE University, Al Ain, United Arab Emirates.

American Diabetes Association (2001). Diabetes 2001 Vital statistics. Alexandra, VA: ADA.

Bennett N, Dodd T, Flatley J, Freeth S, Boiling K (1995). Health survey 
for England 1993, London; HMSO.

Blood A, Hayes TM, Gamble DR (1975). Register of newly diagnosed diabetic children. BMJ. 3:580-583.

Bjorntorp P (1992). Abdominal fat distribution and disease: an overview of epidemiological data. Annals Med. 24(1):15-18.

Bonadonna RC, Saccomani MP, Seely L, et al. (1993). Glucose transport in human skeletal muscle: the in vivo response to insulin. Diabetes. 42:191-198.

Campbell IT, Kay TWH, Oxbrow L, Harrison TC (1991). Essential role for Interferon Gama and interleukin 6 in autoimmune, insulindependent diabetes in NOD/Wehi mice. J. Clin. Invest. 87:739-742.

Comi RJ, Grunberger G, Gorden P (1987). Relationship of insulin binding and Insulin-stimulated tyrosine kinase activity is altered in type II diabetes. J. Clin. Invest. 79:453-62.

Chan JC, Malik V, Jia W, Kadowaki T, Yajnik CS, Yoon KH, Hu FB (2009). Diabetes in Asia; epidemiology, risk factors, and pathophysiology. JAMA, 301:2129-2140.

Colagiuri S (2010). Diabesity; Therapeutic Options. Diabetes Obes. Metab. 12:463-473.

Cook JT, Hattersley AT, Levy JC, Patel P, Wainscoat JS, Hockaday TD, Turner RC (1993). Distribution of Type II diabetes in nuclear families. Diabetes. 42:106-12.

Defronzo RA, Ferrannini E (1988). Lily Lecture 1987. The Triumvirate: Beta Cell, Muscle, Liver. A Collusion Responsible for NIDDM. Diabetes. 37:667-687.

Enoki S, Mitsukawa T, Takemura J, Nakazato M, Aburaya J, Toshimori H, Matsukara S (1992). Plasma islet amyloid polypeptide levels in obesity, impaired glucose tolerance and non-insulin-dependent diabetes mellitus. Diabetes Res. Clin. Pract. 15(I):97-102.

EURODIAB ACE Study Group (2000). Variation and trends in incidence of childhood diabetes in Europe, Lancet. 335:873-876.

Evephart JE, Pettit DJ, Bennett PH, Knowler WC (1992). Duration of obesity increases the incidence of NIDDM. Diabetes. 41:235-240.

Felber JP (1992). From obesity to diabetes: pathophysiological considerations. Int. J. Obes. 1992; 16:937-952.

Fowell D, Mcknight Al, Powrie F, Dyke R, Mason D (1991). Subsets of CD4+ $T$ cells and their roles in the induction and prevention of autoimmunity. Immunol. Rev. 123:37-64.

Froguel $\mathrm{P}$, Zouali $\mathrm{H}$, Vionnet N, Velho G, Vaxillaire M, Sun F, Lesage S, Stoffel M, Takeda J, Passa P,Permutt MA,Beckmann JS, Bell GI, Cohen D (1993). Familial hyperglycemia due to mutations in glucokinase definition of a subtype of diabetes mellitus. $\mathrm{N}$ Engl $\mathrm{J}$ Med. 328(10):697-702.

Gabbay K H (1980). The Insulinopathies. N. Engl. J. Med. 302:165-7.

González EL, Johansson S, Wallander MA, Rodríguez LA (2009). Trends in the prevalence and incidence of diabetes in the UK: 1996 2005. J. Epidemiol. Community Health. 63: 332-336.

Gill RG, Haskins K (1993). Molecular mechanisms underlying diabetes and other autoimmune diseases. Immunol. Today. M:49-51.

Guyton AC, Hall JE (2006). Textbook of Medical physiology. $11^{\text {th }}$ Edition. Elsevier Inc, New Delhi.

Haffner SM, Mitchell BD, Stern MP, Hazuda HP, Patterson JK (1992). Public health significance of upper body adiposity for non-insulin dependent diabetes in Mexican Americans. Int. J. Obes. 16(3):177184.

Hattersley AT, Turner RC, Permutt MA, Patel P, Tanizawa Y, Chiu KC, O'Rahilly S, Watkins P, Wainscoat JS (1992). Linkage of type 2 diabetes to the glucokinase gene. Lancet. 339:1307-1310.

Holt G. I. (2004). Diagnosis, epidemiology and pathogenesis of diabetes mellitus an update for Psychiatrists. Br. J. Psychiatry. 184:s55- s63.

Joffe BI, Panz VR, Wing JR, Raal FJ, Seftel HC (1992). Pathogenesis of noninsulin- dependent diabetes mellitus in the black population of southern Africa. Lancet. 340(8817):460-462.

Kahu RC, White MF (1988). The insulin receptor and the molecular mechanism of insulin action. J. Clin. Invest. 82:1151.

Kaku K (2010). Pathophysiology of type 2 diabetes and its treatment policy. JMAJ, 53(1):41-46.

Kaprio J, Tuomilehto J, Koskenvuo M, Romanov K, Reunanen A,
Eriksson J, Stengård J, Kesäniemi YA (1992); Concordance for Type 1 (insulin dependent) and Type 2 (non-insulin-dependent) diabetes mellitus in population based cohort of twins in Finland. Diabetologia, 35:1060-1067.

Karvonen M, Pitkaniemi J, Tuomilehto J (1999). The onset age of type 1 diabetes in Finnish children has become younger. The Finnish childhood diabetes Registry Group. Diabetes care. 22:1066-1070.

Knowler WC, Nelson RG, Saad MF, Bennett PH, Pettitt DJ (1993). Determinants of diabetes mellitus in the Pima Indians. Diabetes Care. 16:216-227.

Knowler WC, Pettitt DJ, Sadd M, Bennett PH (1990). Diabetes mellitus in the Pina Indians: incidence, risk factors and pathogenesis. Diabetes/Metab.Rev 6:1-27.

Kolb, H, Kolb-bachofen (1992). Nitric oxide a pathogenetic factor in autoimmunity. Immunol. Today, 13:157-159.

Kolb-bachofen V, Epstein SQ, Kiesel U, Kolb H (1988). Low dose streptozocin induced diabetes in mice. Electron microscopy reveals single-cells insulitis before diabetes onset. Diabetes. 37:21-27.

Kroncke KD, Kolb-bachofen V, Berschick B, Burkart V, Kolb H (1991). Activated macrophages kill pancreatic syngeneic islet via argininedependent nitric oxide generation. Biochem. Biophys. Res. Commun.175:752-758.

Levy JR, Hug V (1993). Nuclear protein-binding analysis of a GC-rich insulin-receptor promotor regulator region. Diabetes, 42: 66-73.

Lukic ML, Al-sharif R, Mostarica M, Bahr G, Behbehani K (1991). Immunological basis of the strain differences in susceptibility to lowdose streptozotocininduced diabetes in rats. In: Lymphatic Tissues and In vivo Immune Responses . Eds. Imhof. et. al.; New York. Marcel Dekker Inc. pp 643-647.

Lukic ML, Stosic-Grujicic S, Ostojic N, Chan WL, Liew FY (1991). Inhibition of nitric oxide generation affects the induction of diabetes by streptozotocin in mice. Biochem. Biophys. Res. Commun. 178:913-920.

Mandrup-poulsen T, Spinas GA, Prowse SJ, Hansen BS, Jorgensen DW, Bendtzen K, Nielsen JH, Nerup J (1987). Islet cytotoxicity of interleukin-I. Influence of culture conditions and islet donor characteristics. Diabetes, 1987;36:641-647.

McVeigh GE, Brennan GM, Johnston GD, McDermott BJ, McGrath LT, Henry WR, Andrews JW, Hayes JR (1993). Dietary fish oil augments nitric oxide production or release in patients with type 2 (non-insulindependent) diabetes mellitus. Diabetologia. 36:33.-38.

Molina JM, Cooper GIS, Leighton B, Olefsky JM (1990). Induction of insulin resistance in vivo by amylin and calcitonin gene-related peptide. Diabetes. 39:260-5.

Mueckler M (1990). Family of glucose-transporter genes: implications for glucose homeostasis and diabetes. Diabetes. 39:6-11.

National Diabetes Data Group (1979). Classification and diagnosis of diabetes mellitus and other categories of glucose intolerance. Diabetes. 28:1039-1057.

Neil HA, Gatling W, Mather HM, Thompson AV, Thorogood M, Fowler GH, Hill RD, Mann JI (1987). The Oxford community Diabetes study; evidence for an increase in the prevalence of known diabetes in Great Britain. Diabetic Med. 4:539-543.

Njolstad PR, Sagen JV, Bjorkhaug L, Odili S, Shehadeh N, Bakry D, Sarici, S. U., Alpay, F., Molnes, J., Molven, A., Sovik, O. and Matschinsky, F. M. (2003). Permanent neonatal diabetes caused by glucokinase deficiency: inborn error of the glucose-insulin signaling pathway. Diabetes. 52(11):2854-60.

Wilson PW, Mcghee DL, Kannel WB (1981). Obesity, very low density lipoproteins and glucose intolerance over fourteen years: the Framingham study. Am. J. Epidemiol. 114:697-704.

Oelbaum RS (1992). Analysis of three glucose transporter genes in a Caucasian population:no associations with non insulin-dependent diabetes and obesity. Clin. Genet. 42:260- 266.

Ohagi S, Ekawa K, Sanke K, Nishi M, Nanjo K (1992). Restriction fragment length polymorphisms near the islet amyloid polypeptide gene in Japanese subjects. Diabetes Res. Clin. Pract.18:71-74

Raju SM, Raju B (2010). Illustrated medical biochemistry. $2^{\text {nd }}$ Edition. 
Jaypee Brothers Medical Publishers Itd, New Delhi, India. 645pp

Richens ER, Abdella N, Jayyab AK., Alsaffar M, Behbehani K (1988); Type 2 Diabetes in Arab patients in Kuwait. Diabetic Med. 5:231-234.

Rowley WR, Bezold C. (2012)."Creating public awareness: state 2025 diabetes forecasts." Population Health Management. 15.

Shaw JE, Sicree RA, Zimmet PZ (2010). Global estimates of the prevalence of diabetes for 2010 and 2030. Diabetes Res. Clin. Pract. 87:4-14.

Steiner DF, Ohagi S, Nagamatsu S, Bell GI, Nishi M (1991). Is Islet Amyloid Polypeptide a Significant Factor in Pathogenesis or Pathphysiology of Diabetes. Diabetes. 40(3):305-309.

Sten-Linder M, Wedell A, Iselius L, Efendic S, Luft R, Luthman H (1993). DNA polymorphisms in the human tyrosine hydroxylase/insulin/insulin-like growth factor II chromosomal region in relation to glucose and insulin responses. Diabetologia. 36:25-32.

Tattershall RB (1991). Maturity-onset diabetes of the young (MODY) in Pickup and Williams. Textbook of Diabetes. 1:246.

Ulaeto D, Lacy PE, Kipnis DM, Kanagawa O, Unanue ER (1992). A Tcell dormant state in the autoimmune process of non-obese diabetic mice treated with complete Freund's adjuvant. Proc. Natl. Acad. Sci. USA, 89:3927-3931.
Vionnet N, Stoffel M, Takeda J, Yasuda K, Bell GI, Zouali H, Lesage S, Velho G, Iris F, Passa P (1992). Nonsense mutation in the glucokinase gene causes early-onset non-insulin-dependent diabetes mellitus. Nature. 356:721-722.

Vuorinen-Markkola H, Koivisto VA, Ykijarvinen H (1992). Mechanisms of hyperglycemia-induced insulin resistance in whole body and skeletal muscle of type 1 diabetic patients. Diabetes. 41:571-580.

Westermark P (1973). Fine Structure of Islets of Langerhans in Insular Amyloidosis. Vichows Arch. Path. Anat. 359:1-18.

Yagi H, Matsumoto M, Kunimoto K, Kawaguchi J, Makino S, Harada M (1992). Analysis of the roles of CD4+ T cells in autoimmune diabetes of NOD mice using transfer to NOD male mice. Eur. J. Immunol. 22:2387-2393.

Zavala AV, Fabiano de Bruno LE, Cardoso Al, Mota AH, Capucchio M, Poskus E, Fainboim L, Basabe JC (1992). Cellular and humoural autoimmunity markers in Type 2 (non-insulin-dependent.) diabetic patients with secondary drug failure. Diabetologia. 35:1159-1164. 